\title{
Larval fitness, microsatellite diversity and MHC class II diversity in common frog (Rana temporaria) populations
}

\author{
I Zeisset and TJC Beebee \\ Department of Biochemistry, School of Life Sciences, University of Sussex, Falmer, Brighton, UK
}

\begin{abstract}
There is increasing interest in using functional rather than neutral loci to assess the genetic health of wild populations. We compared growth and survival of urban and rural frog larvae under three temperature regimes, to vary stress levels, and measured genetic diversities at nine microsatellites and at one major histocompatibility complex (MHC) class II locus. We found no significant differences between urban and rural frogs in larval survivorship, nor in microsatellite and $\mathrm{MHC}$ diversities. However, mean larval growth rates were significantly higher (by $4.5-18.9 \%$ according to temperature) in urban compared with rural populations. Microsatellite and $\mathrm{MHC}$ diversities were uncorrelated, though pairwise inter-site $F_{\mathrm{ST}}$ estimates based on the two types of loci were correlated. MHC $F_{\mathrm{ST}}$ estimates averaged about twice as high as those based on microsatellites. There was
\end{abstract}

Keywords: MHC; microsatellite; amphibian; larval fitness

\section{Introduction}

The use of highly polymorphic neutral markers, especially microsatellites, has greatly increased understanding of wild animal and plant population genetics over the past decade (Balloux and Lugon-Moulin, 2002; Storfer et al., 2007). These loci have provided insights into areas as diverse as population history, structure, effective size and migration patterns. They have also, by facilitating individual identification, dramatically improved knowledge about sexual and kin selection in a wide range of species (Knopp et al., 2008; Uller and Olsson, 2008). However, one area in which the use of neutral markers has been contentious for decades concerns the relationship between neutral genetic diversity, adaptive variation and fitness (Reed and Frankham, 2003). Conservation biologists have often hoped or assumed that neutral genetic diversity reflects adaptive variation, and can thus act as a surrogate indicator of population genetic health. Empirical results in this field have, however, been inconsistent. At the individual level, correlations between neutral diversity and fitness mea-

Correspondence: Professor TJC Beebee, Department of Biochemistry, School of Life Sciences, University of Sussex, Falmer, Brighton BN1 9QG, UK.

E-mail: t.j.c.beebee@sussex.ac.uk

Received 17 April 2009; revised 7 September 2009; accepted 20

October 2009; published online 18 November 2009 no evidence of isolation by distance with either marker. There were no correlations at the population level between any larval fitness attribute (growth rate or survival) and any diversity estimate (microsatellite or $\mathrm{MHC}$ ). There was, however, a weak correlation at the sibship level between mean growth rate and microsatellite expected heterozygosity. MHC alleles varied among dying larvae and survivors, and in one case between urban and rural sites, with one allele being underrepresented in dying larvae and one allele only occurring in the rural sites. Drift was probably the primary cause of genetic population structure at both types of loci. The use of functional loci to assess population genetic health should focus on the roles of specific alleles as well as overall diversity.

Heredity (2010) 104, 423-430; doi:10.1038/hdy.2009.157; published online 18 November 2009

sures are often weak and explain very little of the variance (Butlin and Tregenza, 1998; Reed and Frankham, 2001). Among populations, stronger correlations are detected more often, especially when the sample includes small and potentially inbred populations (Reed and Frankham, 2003). Nevertheless, low diversity at neutral loci can sometimes be explained by factors unrelated to fitness, such as patterns of postglacial population expansion (Ficetola et al., 2007).

Ideally, therefore, genetic studies of population viability should focus on loci under selection. For most nonmodel organisms few such loci have thus far been characterized, but the major histocompatibility complex (MHC) in vertebrates is a notable exception (Piertney and Oliver, 2006). Vertebrates have at least two classes of MHC loci, all of which code for membrane-bound proteins central to the immune response. Class I loci are expressed in most tissues and recognize intracellular pathogens such as viruses. Class II loci are expressed mostly in lymphocytes and are involved in responses to extracellular pathogens such as bacteria and fungi. Species vary in the number of genes they have in each MHC class (Kelley et al., 2005), but in general they are the most polymorphic protein-encoding loci thus far discovered. MHC loci are clearly under selection, and therefore provide a useful tool with which to investigate adaptive variation in vertebrates.

Amphibians are interesting subjects for such studies, particularly because many species around the world are 
declining or have already gone extinct as a result of an emerging pathogen, the fungus Batrachochytrium dendrobatidis (Beebee and Griffiths, 2005) and other diseases such as ranavirus, Aeromonas hydrophila as well as factors such as habitat loss and degradation that also strongly affect amphibian populations. Amphibians also typically exhibit high levels of population structure over relatively small geographical distances (Beebee, 2005). As yet, however, there have been few studies of amphibian MHC diversity. Among anurans, MHC loci have been characterized in Xenopus laevis, Bombina bombina and, recently, a class I locus in Rana temporaria (Sato et al., 1993; Hauswaldt et al., 2007; Teacher et al., 2009). Investigations combining $\mathrm{MHC}$ and fitness (disease resistance) analyses have so far only been carried out in X. laevis (Gantress et al., 2003; Barribeau et al., 2008) and $R$. temporaria (Teacher et al., 2009)

We have characterized an expressed, polymorphic region (part of exon 2) of an MHC class II $\beta$ locus in $R$. temporaria, the common frog of northern Europe (Zeisset and Beebee, 2009). This region encodes the $\beta 1$ domain, which constitutes part of the peptide-binding domain and therefore may have an important function in the immune response. Other studies have shown that certain genotypes at $\mathrm{MHC}$ loci can confer disease resistance in amphibians (Barribeau et al., 2008). As earlier work (Hitchings and Beebee, 1997) indicated that urban populations of $R$. temporaria were on average smaller, more isolated and exhibited higher levels of larval mortality and developmental abnormalities than rural populations, we set out to test the hypotheses that (i) the larval fitness traits of survival and growth rate vary among frog populations in urban and rural habitats, (ii) variance in these traits correlates more strongly with diversity at MHC loci than with diversity at microsatellite loci, and (iii) that survival correlates with specific MHC alleles.

\section{Materials and methods}

\section{Sample collection and fitness assessments}

During the spring of 2008, we collected around 20 eggs from each of nine spawn clumps from each of four rural and four urban R. temporaria populations in Sussex, UK, except for one urban population (Woodingdean) where only seven spawn clumps were found. The rural sites corresponded to four of the five populations (A, Ashdown Forest; B, Offham marshes; C, Pevensey; and D, Chichester) sampled in an earlier study of this species, and two of the urban sites (Hillside Way and Hove Park Way) corresponded to populations (six and eight) of eight urban populations investigated in the same study (Hitchings and Beebee, 1997). The remaining urban sites from Hitchings and Beebee (1997) were no longer accessible, so two new ones including a population (Woodingdean) decimated by a Ranavirus outbreak in 2007 were included. We used fewer populations in this study, to make more detailed investigations of each. In the earlier study (Hitchings and Beebee, 1997), batches of 100 larvae from each site were reared together and survival was assessed. In this study, we measured growth rates of individual larvae, as well as survivorship, as fitness indicators. Numbers of spawn clumps in urban sites $($ all $<20)$ tended to be fewer than numbers in rural sites (all $>15$, up to $>100$ ) but we did not attempt to estimate census or effective population sizes because amphibian numbers can vary at any particular pond by an order of magnitude over decadal time periods, and because ponds are not closed systems with respect to frog populations (Beebee and Griffiths, 2005).

The eggs from each spawn clump were kept separately in 11 beakers filled with $900 \mathrm{ml}$ aged, dechlorinated tap water and $100 \mathrm{ml}$ pond water (from one source, Chichester) at $15^{\circ} \mathrm{C}$ until hatching. Pond water was added as a source of extra pathogens, such as the water fungus Saprolegnia spp. that causes mortality in amphibian embryos and larvae (Romansic et al., 2009) and A. hydrophila, which causes larval as well as adult deaths (Cunningham et al., 1996). All the eggs and larvae were therefore exposed to a cocktail of pond microfauna, without attempting to identify or amplify individual components, to generate as natural a situation as possible. Pathogens such as Saprolegnia are ubiquitous in fresh waters all over the world, and controls lacking pathogens are therefore impossible because spawn is taken from ponds containing pathogens. Once the larvae were free swimming at around stage 26 (Gosner, 1960) three from each clutch were placed individually in 11 beakers filled with $900 \mathrm{ml}$ aged dechlorinated tap water and $100 \mathrm{ml}$ pond water, and each was allocated to a temperature treatment: $\operatorname{cold}=10 \pm 1{ }^{\circ} \mathrm{C}$, medium $=$ $14 \pm 2{ }^{\circ} \mathrm{C}$ and warm $=21 \pm 4{ }^{\circ} \mathrm{C}$ ), all under strictly controlled conditions and with a 12:12 h light-dark cycle. Temperature was varied to subject larvae to different stress regimes, thus increasing the chances of detecting genetic diversity $\times$ fitness correlations. Fungal infection of $R$. temporaria embryos and larvae, resistance to which could be MHC related, is enhanced by cold conditions (Beattie et al., 1991). Water temperatures in frog breeding sites regularly vary over the range we used. For each there were three temperature-controlled baths, into which individuals in the beakers were randomly allocated. These baths were included as potential block effects in subsequent analyses. The larvae were fed $a d$ libitum with rodent pellets twice weekly, deaths were recorded (and the individuals preserved), and every individual was measured at weekly intervals. The experiment was terminated after 5 weeks when growth at the higher temperature started to deviate from linearity, at which point we preserved tail clippings of the larger tadpoles or whole small tadpoles in $96 \%$ ethanol for later genetic analysis. Growth rate was estimated as the slope of the growth over time (which was generally linear over the experiment) obtained for each tadpole.

\section{DNA extraction}

DNA was extracted from all the larvae using GenElute Mammalian Genomic DNA miniprep kits (Sigma-Aldrich, Gillingham, Dorset, UK) and stored at $-20^{\circ} \mathrm{C}$ until required.

Microsatellite analyses: We assayed diversity at the following nine microsatellite loci: RT $\mu \mathrm{P}$ (Pidancier et al., 2002), RtSB14, RtSB3, RtSB80 (Berlin et al., 2000), Rtemp $\mu 1$, Rtemp $\mu 2$, Rtemp $\mu$ 4, Rtemp $\mu 7$ and Rtemp $\mu 8$ (Rowe and Beebee, 2001a). Twenty-microlitre PCRs contained $1 \times$ PCR buffer (New England Biolabs, Hitchin, Herts, UK), $100 \mu \mathrm{M}$ each of dCTP, dGTP and dTTP, $5 \mu \mathrm{M}$ unlabelled dATP and $7 \mathrm{KBq}\left[\alpha^{33} \mathrm{P}\right]-\mathrm{dATP}, 0.5$ units of 
Taq DNA polymerase (New England Biolabs), $0.2 \mu \mathrm{M}$ of each primer and $\sim 25-100 \mathrm{ng}$ of DNA. Thermal cycling was carried out with a starting cycle of $94{ }^{\circ} \mathrm{C}$ for $3 \mathrm{~min}$, 30-35 cycles of $94^{\circ} \mathrm{C}$ for $40 \mathrm{~s}$, primer-specific annealing temperature for $40 \mathrm{~s}$ and extension at $72^{\circ} \mathrm{C}$ for $1 \mathrm{~min}$, followed by a final extension cycle of $72{ }^{\circ} \mathrm{C}$ for $5 \mathrm{~min}$. Annealing temperatures were either (a) two cycles each at $66,64,62,60,58$ and then 25 at $56^{\circ} \mathrm{C}$; (b) two cycles each at $62,60,58,54$ and then 27 at $52^{\circ} \mathrm{C}$; or (c), 10 cycles gradually decreasing from 60 to 55 followed by 20 cycles at $55^{\circ} \mathrm{C}$. We multiplexed loci Rtemp $\mu 4$ and Rtemp $\mu 7$, or RtSB80 and RtSB14, using PCR conditions (a) and Rtemp $\mu 2$ and RT $\mu \mathrm{P}$ under PCR conditions (b). Rtemp $\mu 8$ was amplified using PCR conditions (a) and Rtemp $\mu 1$ and RtSB3 were amplified using PCR conditions (c). PCR products were analysed by electrophoresis through standard sequencing gels [6\% (w/v) polyacrylamide], followed by autoradiography. M13 sequence markers were used to size the PCR products.

\section{MHC analyses}

MHC genotypes (148 bp fragments of exon 2) at a class II $\beta$ locus were determined for all larvae as described by Zeisset and Beebee (2009). Twenty-microlitre PCRs contained $1 \times$ PCR buffer (New England Biolabs), $100 \mu \mathrm{M}$ of dCTP, dGTP and dTTP, $5 \mu \mathrm{M}$ unlabelled dATP and $7 \mathrm{KBq}\left[\alpha^{33} \mathrm{P}\right]-\mathrm{dATP}, 0.5$ units of Taq polymerase (New England Biolabs), $0.2 \mu \mathrm{M}$ of each primer (RTMHCF and RTMHCR) and $\sim 25-100 \mathrm{ng}$ of DNA. Thermal cycling included one cycle of $94^{\circ} \mathrm{C}$ for $3 \mathrm{~min}$, then 35 cycles of $94{ }^{\circ} \mathrm{C}$ for $40 \mathrm{~s}, 57^{\circ} \mathrm{C}$ for $40 \mathrm{~s}$ and $72{ }^{\circ} \mathrm{C}$ for $1 \mathrm{~min}$ followed by a final extension of $72{ }^{\circ} \mathrm{C}$ for $5 \mathrm{~min}$. We used SSCP analysis to identify MHC alleles. PCR products were mixed with $12 \mu \mathrm{l}$ of loading dye (95\% formamide, $20 \mathrm{mM}$ EDTA, $0.05 \%$ bromophenol blue and $0.05 \%$ xylene cyanol), heated at $95^{\circ} \mathrm{C}$ for $3 \mathrm{~min}$ and then placed on ice. Six microlitres of each sample were loaded onto a $0.5 \times \mathrm{MDE}$ (Lonza) gel containing 10\% glycerol and $0.6 \times$ TBE $(1 \times$ TBE $=90 \mathrm{mM}$ Tris, $0.18 \mathrm{M}$ boric acid, $2 \mathrm{mM}$ EDTA) and run at 5-15 Watts in $0.6 \times$ TBE for $16-19 \mathrm{~h}$ at room temperature. Samples with alleles that did not differentiate well on this gel were run again on a gel with $1 \times$ TBE buffer at 3-5 Watts. Gels were dried and the banding patterns visualized using phosphorimager screens. One allele (Y) not detected in the earlier study was sequenced to confirm identity (Genbank accession number: FJ876299).

\section{Data analysis}

Larval survivorship was compared among populations and among groups (urban and rural) using multi-sample survival tests. Growth rates were compared among populations and groups, taking account of block effects, using either parametric or Kruskal-Wallis analysis of variance, according to whether data were normally distributed. Analysis of variance models with growth rate as the dependent variable included temperature and group, temperature and population or temperature and clutch as independent variables, together with possible interactions between each pair. All these analyses used STATISTIX ver. 7 (Analytical Software, Tallahassee, FL, USA). Mortality was compared using non-parametric Gehan-Wilcoxon, log-rank or Pet-Wilcoxon multi-sample tests, based on individual survival times, and with probabilities estimated using $\chi^{2}$ statistics.

The microsatellite and MHC data were tested for the presence of null alleles and scoring errors using MICROCHECKER (Van Oosterhout et al., 2006). For the microsatellites, concordance with Hardy-Weinberg (HW) equilibrium and linkage equilibrium, observed and expected heterozygosities $\left(H_{\mathrm{O}}\right.$ and $\left.H_{\mathrm{E}}\right)$ as well as allele frequencies were calculated using GENEPOP ver.4 (Rousset, 2008). Microsatellite loci were also checked for evidence of selection (presumably acting through linkage disequilibrium) using LOSITAN (Antao et al., 2008). All the populations were checked for evidence of recent contraction using BOTTLENECK (Cornuet and Luikart, 1996), with a $90 \%$ stepwise mutation model, $30 \%$ variance and 1000 replications. Pairwise $F_{\mathrm{ST}}$ estimates and allelic richness were calculated in FSTAT v 2.9.3 (Goudet, 1995). As the MHC locus showed evidence of at least one null allele, heterozygosity and $F_{\mathrm{ST}}$ estimates taking account of null allele frequency estimates were calculated using FreeNA (Chapuis and Estoup, 2007). We used the suboption ISOLDE in GENEPOP to investigate isolation by distance (IBD) between the populations, using microsatellite and MHC data, based on direct (straight line) geographical distances. We used the same approach, also with Mantel tests, to investigate correlations between microsatellite and MHC $F_{\mathrm{ST}}$ estimates.

Correlations between fitness and genetic data were investigated using Spearman rank estimates in STATISTIX ver. 7. Analyses were performed at up to three levels of scale, as appropriate: group ( $n=2$, urban and rural); population (sampling ponds, $n=8$ ); and sibship (egg clutch, $n=70$ ).

\section{Results}

\section{Mortality and growth rates}

The results of the fitness experiment are summarized in Table 1. Overall mortality was around 9\% (9 individuals) for urban populations and 10\% (11 individuals) for rural populations. Mortality was randomly distributed among groups, populations, clutches and temperatures, with no significant differences at any level. Low and high temperatures therefore resulted in no extra stress detectable in mortality rates.

Growth rates differed greatly according to temperature with rates at $21^{\circ} \mathrm{C}$ approximately three times faster, on average, than those at $10^{\circ} \mathrm{C}$. Block effects were only apparent in the low temperature regime (analysis of variance $\mathrm{F}=5.76, \mathrm{df}=3.64, P=0.002$ ), and there were significant mean growth rate differences between the urban and rural groups, but no significant interaction between group and temperature (analysis of variance $\mathrm{F}$ (temperature) $=415.1, \mathrm{~F}$ (groups) $=9.9, \mathrm{~F}$ (interactions) $=0.8, \mathrm{df}=1,2,2, P \leqslant 0.001, P=0.002$, $P=0.471$ respectively). According to temperature, urban larvae grew $4.5-18.9 \%$ faster than rural ones. Variance in growth rates across the three temperature regimes was consistently higher (averaging 1.7-fold) in the rural relative to the urban group. There were also significant differences among populations in mean growth rates under all three temperature regimes, again with no interaction $(\mathrm{F}$ (temperature $)=468.4, \mathrm{~F}$ (population $)=5.4$, $\mathrm{F}($ interaction $)=1.5, \mathrm{df}=7,2,14, P \leqslant 0.001, P \leqslant 0.001$, 
Table 1 Larval fitness comparisons

\begin{tabular}{|c|c|c|c|c|c|c|c|c|c|c|c|c|}
\hline \multirow[t]{3}{*}{ Populations } & \multicolumn{4}{|c|}{ Low temperature } & \multicolumn{4}{|c|}{ Medium temperature } & \multicolumn{4}{|c|}{ High temperature } \\
\hline & \multicolumn{2}{|l|}{ Mortality } & \multicolumn{2}{|c|}{ Growth rate } & \multicolumn{2}{|l|}{ Mortality } & \multicolumn{2}{|c|}{ Growth rate } & \multicolumn{2}{|l|}{ Mortality } & \multicolumn{2}{|c|}{ Growth rate } \\
\hline & No. of deaths & $\mathrm{n}$ & Mean & s.d. & No. of deaths & $\mathrm{n}$ & Mean & s.d. & No. of deaths & $\mathrm{n}$ & Mean & s.d. \\
\hline \multicolumn{13}{|l|}{ Rural } \\
\hline Chichester & 0 & 9 & 0.39 & $(0.06)$ & 0 & 9 & 0.92 & $(0.13)$ & 0 & 9 & 1.11 & $(0.15)$ \\
\hline Offham & 2 & 9 & 0.35 & $(0.10)$ & 0 & 9 & 0.89 & $(0.14)$ & 1 & 8 & 1.07 & $(0.14)$ \\
\hline Ashdown & 1 & 9 & 0.39 & $(0.06)$ & 0 & 9 & 1.15 & $(0.31)$ & 2 & 7 & 1.18 & $(0.35)$ \\
\hline Pevensey & 2 & 9 & 0.36 & $(0.06)$ & 2 & 9 & 1.10 & $(0.15)$ & 1 & 9 & 1.04 & $(0.16)$ \\
\hline \multicolumn{13}{|l|}{ Urban } \\
\hline Hove Park Way & 0 & 9 & 0.44 & $(0.07)$ & 0 & 9 & 1.02 & $(0.15)$ & 0 & 9 & 1.16 & $(0.12)$ \\
\hline Warnham Rise & 1 & 9 & 0.45 & $(0.07)$ & 2 & 7 & 0.97 & $(0.27)$ & 0 & 9 & 1.23 & $(0.12)$ \\
\hline Hillside Way & 1 & 8 & 0.43 & $(0.09)$ & 2 & 8 & 1.02 & $(0.17)$ & 2 & 7 & 1.13 & $(0.16)$ \\
\hline Woodingdean & 1 & 6 & 0.45 & $(0.03)$ & 0 & 7 & 1.23 & $(0.13)$ & 0 & 7 & 1.33 & $(0.09)$ \\
\hline
\end{tabular}

$n$ is the number of individuals measured for growth rate (including some that died late in the trials). Growth rates are in mm per day.

$P=0.103$ respectively), Finally, there were also significant differences in growth rates among larvae from different clutches $(\mathrm{F}$ (temperature $)=521.4, \mathrm{~F}($ clutch $)=2.1, \mathrm{df}=7$, $20, P \leqslant 0.001, P \leqslant 0.001$ respectively).

\section{Genetic variation}

Tests with MICROCHECKER showed that the Chichester population had homozygote excesses at six out of the nine microsatellite loci. Among the other seven populations, homozygote excess was only indicated in four out of 63 tests. The MHC locus, however, had homozygote excess, due to a null allele, in all populations as found in an earlier study with frogs elsewhere in Sussex (Zeisset and Beebee, 2009). GENEPOP tests for HW equilibrium indicated, after Bonferroni correction for significance at $P<0.05$, only seven out of 72 cases of deviation from HW expectations in the microsatellite data, randomly distributed among populations and loci. However, four out of 36 locus-pair combinations were significantly in linkage disequilibrium across all the populations (Rtemp4 × RtSB3; Rtemp4 × RTBS80; Rtemp4 × RTSB14; and RTSB3 $\times$ RTSB80). Furthermore, in $F_{\text {ST }}$ analyses with LOSITAN locus RtSB80 was a $>99 \%$ outlier on which effects of selection could not be discounted. On the basis of the linkage disequilibrium and outlier results, we therefore excluded loci Rtemp4 and RtSB80 from subsequent analyses.

Genetic diversities of the populations at the seven remaining microsatellite loci and at the MHC locus are shown in Table 2. These include estimates of MHC null allele frequency and $H_{\mathrm{E}}$ with or without this assumption of HW equilibrium. At the sibship level, there were significant correlations between $H_{\mathrm{E}}$ and allelic richness for both microsatellite $\left(r_{\mathrm{s}}=0.243, P=0.043\right)$ and MHC $\left(r_{\mathrm{s}}=0.598, P=0.0001\right)$ loci. There were significant differences among sibships for microsatellite $H_{\mathrm{E}}$ (KW statistic $=100.30, P=0.0008)$ and for $\mathrm{MHC} H_{\mathrm{E}}(\mathrm{KW}$ statistic $=128.47, P \leqslant 0.0001)$. However, there were no significant differences in any of the diversity estimates (allelic richness and $H_{\mathrm{E}}$ for microsatellites and MHC) among populations or between the urban and rural groups. No populations gave any indication of recent bottlenecks using either the Wilcoxon or mode-shift tests.
Pairwise (inter-population) $F_{\mathrm{ST}}$ estimates based on the seven microsatellite loci and on the MHC locus after null-allele correction are shown in Table 3 . The overall mean pairwise MHC $F_{\mathrm{ST}}$ estimate (0.099) was almost twice the overall mean microsatellite $F_{\mathrm{ST}}$ estimate $(0.051)$, a significant difference by Wilcoxon sign rank test $(P=0.0018)$. In this respect, there were, however, differences between the groups. Mean rural pairwise $F_{\text {ST }}$ estimates (six comparisons) were essentially the same for both types of loci (microsatellite $=0.050$; $\mathrm{MHC}=$ 0.051), whereas the mean urban $F_{\mathrm{ST}}$ pairwise estimates, also with six comparisons, (microsatellite $=0.052$, $\mathrm{MHC}=0.121)$ were markedly different. In the 16 urban $\times$ rural comparisons of pairwise $F_{\mathrm{ST}}$ estimates, the mean for MHC (0.110) was significantly greater than the microsatellite mean of $0.052(P=0.0011)$. Neither type of loci showed significant IBD. However, despite the quantitative differences in $F_{\mathrm{ST}}$ estimates described above, there was an overall correlation between microsatellite and MHC $F_{\mathrm{ST}}$ estimates across all population pairs (Mantel test, 10000 permutations, $P=0.054$ ).

\section{Genetic diversity and fitness measures}

Larvae dying during the treatments, and from which genotypes were successfully obtained ( $n=16$ for microsatellites, $n=14$ for MHC), did not differ from survivors with respect to mean heterozygosity or allelic richness at either type of loci. At the sibship level, there was a weak correlation between microsatellite $H_{\mathrm{E}}$ and mean growth rate across the three temperatures $\left(n=70 ; r_{\mathrm{s}}=0.231\right.$, $P=0.055)$, but there were no significant correlations among any of the other genetic diversity estimates and growth. At the population level, no significant correlations were detected between mean larval growth rates at any temperature and allelic richness or $H_{\mathrm{E}}$ of microsatellites or MHC loci. There was, however, a tendency towards negative correlations between population-level variance in growth rate (across all temperatures) and $H_{\mathrm{E}}$, and allelic richness, of both microsatellite and MHC loci. All four correlations $\left(r_{\mathrm{s}}\right)$ were $<-0.5$, but only that for microsatellite $H_{\mathrm{E}}$ was significant $\left(r_{\mathrm{s}}=-0.934, P=0.004\right)$. In other words, populations with a high variance in growth rate had low microsatellite $H_{\mathrm{E}}$ and vice versa. 
Table 2 Genetic diversity estimates

\begin{tabular}{|c|c|c|c|c|c|c|c|c|c|}
\hline \multirow[t]{2}{*}{ Populations } & \multicolumn{4}{|c|}{ Microsatellites } & \multicolumn{5}{|c|}{$M H C$} \\
\hline & $\mathrm{n}$ & Allelic richness & $H_{O}$ & $H_{E}$ & Allelic richness & $H_{O}$ & $H_{E}$ & $H_{E}(+n a)$ & $\begin{array}{l}\text { Null allele } \\
\text { frequency }\end{array}$ \\
\hline \multicolumn{10}{|l|}{ Rural } \\
\hline Chichester & 27 & $6.86(4.00)$ & $0.66(0.16)$ & $0.72(0.14)$ & 4.00 & 0.16 & 0.75 & 0.78 & 0.3265 \\
\hline Offham & 26 & $6.50(3.08)$ & $0.62(0.20)$ & $0.72(0.13)$ & 6.71 & 0.48 & 0.68 & 0.74 & 0.1944 \\
\hline Ashdown & 26 & $6.33(3.29)$ & $0.74(0.18)$ & $0.68(0.13)$ & 3.00 & 0.19 & 0.58 & 0.69 & 0.2048 \\
\hline Pevensey & 25 & $6.38(2.94)$ & $0.68(0.20)$ & $0.71(0.16)$ & 5.00 & 0.54 & 0.75 & 0.79 & 0.0984 \\
\hline \multicolumn{10}{|l|}{ Urban } \\
\hline Hove Park Way & 27 & $5.66(2.23)$ & $0.84(0.11)$ & $0.73(0.12)$ & 4.83 & 0.33 & 0.58 & 0.67 & 0.1553 \\
\hline Warnham Rise & 25 & $5.94(2.42)$ & $0.68(0.21)$ & $0.68(0.11)$ & 4.75 & 0.22 & 0.40 & 0.53 & 0.1235 \\
\hline Hillside Way & 26 & $5.83(3.01)$ & $0.68(0.19)$ & $0.70(0.16)$ & 3.99 & 0.44 & 0.70 & 0.72 & 0.0274 \\
\hline Woodingdean & 27 & $6.78(3.26)$ & $0.77(0.16)$ & $0.73(0.15)$ & 6.96 & 0.48 & 0.74 & 0.79 & 0.1380 \\
\hline
\end{tabular}

Abbreviation: MHC, major histocompatibility complex.

Microsatellite data are averages across seven loci (see text) and MHC data are uncorrected and corrected for null allele(s). Standard deviations of estimates (microsatellites) are given in brackets.

Table 3 Inter-site $F_{\mathrm{ST}}$ estimates

\begin{tabular}{lcccccccc}
\hline Populations & Chichester & Offham & Ashdown & Pevensey & Hove Park Way & Warnham Rise & Hillside Way & Woodingdean \\
\hline Chichester & & 0.068 & 0.085 & -0.002 & 0.094 & 0.186 & 0.089 \\
Offham & 0.023 & & 0.091 & 0.036 & 0.009 & 0.032 & 0.062 \\
Ashdown & 0.070 & 0.040 & & 0.023 & 0.106 & 0.202 & 0.060 \\
Pevensey & 0.042 & 0.044 & 0.078 & & 0.052 & 0.123 & 0.051 \\
Hove Park Way & 0.044 & 0.023 & 0.042 & 0.059 & & 0.009 & 0.022 \\
Warnham Rise & 0.052 & 0.052 & 0.077 & 0.080 & 0.054 & 0.152 & 0.187 \\
Hillside Way & 0.041 & 0.017 & 0.050 & 0.056 & 0.029 & 0.069 & 0.108 \\
Woodingdean & 0.066 & 0.048 & 0.047 & 0.078 & 0.039 & 0.091 & 0.035 \\
\hline
\end{tabular}

Abbreviation: MHC, major histocompatibility complex.

Below diagonal, based on microsatellite data (seven loci); above diagonal, based on MHC (null-allele corrected) data

Table 4 MHC allele frequencies

\begin{tabular}{lcc}
\hline MHC allele & \multicolumn{2}{c}{ Average frequency in } \\
\cline { 2 - 3 } & Urban populations & Rural populations \\
\hline C & 0.42 & 0.34 \\
G & 0.02 & 0.04 \\
H & 0.14 & 0.24 \\
K & 0.05 & 0.11 \\
N & 0.03 & 0.04 \\
R & 0.21 & 0.00 \\
X & 0.02 & 0.03 \\
Y & 0.00 & 0.01 \\
'Null' & 0.12 & 0.19
\end{tabular}

Abbreviation: MHC, major histocompatibility complex.

Table 4 summarizes the frequency of the eight identified MHC alleles, and the putative null allele, in the urban and rural populations. Seven of these alleles (C, G, H, K, N, R and X) were identical to those found earlier in Sussex frog populations. In this study, however, we identified an earlier unknown allele (Y) but did not detect another allele $(\mathrm{O})$ seen in three other populations (Zeisset and Beebee, 2009). Only allele R showed nonrandom association between groups, with a significantly higher prevalence in urban rather than rural populations, from which it was apparently absent altogether (Wilcoxon rank sum test, $P=0.02$ ). The presence of this allele was not associated with individual growth rates at any temperature and was detected in one rural population in our earlier study (Zeisset and Beebee, 2009). However, there was some indication that larvae dying during the treatment had MHC allele frequencies differing from those of survivors, based on numbers of expected genotypes. For this analysis, the seven low-frequency alleles all with expected $n<5$, including the null, were pooled as a single group whereas alleles $\mathrm{C}$ and $\mathrm{H}$ were included separately. Allele $\mathrm{C}$ was over-represented by about $50 \%$, and allele $\mathrm{H}$ was under-represented more than two-fold, in dead larvae compared with expectations from the dataset as a whole $\left(\chi^{2}=4.79, \mathrm{df}=2\right.$, $P=0.08)$.

\section{Discussion}

Studies comparing genetic diversity both at neutral (microsatellite) and adaptive (MHC) loci with fitness traits are novel, and thus far have mostly concerned disease resistance and sexual selection in fish. We report here the first investigation combining microsatellite and MHC diversity estimates with measures of growth rate and survival in larval amphibians. Larval growth rate is a well-characterized fitness attribute in amphibians because it generally correlates with the length of larval period and size at metamorphosis, which in turn influence survival and fecundity (Beebee, 1996). However, fitness effects vary according to circumstance and there can be trade-offs between high rates in predator- 
rich ponds leading to small metamorph size, and lower rates in less dangerous ponds generating larger metamorphs (Werner, 1986). Contrary to earlier findings (Hitchings and Beebee, 1997), we found no significant indications of increased mortality in the urban relative to the rural frog populations. In the earlier study, the urban average mortality was strongly depressed by two out of eight populations with elevated mortality within the first 24 days (that is within the same time frame as this study). Although we only investigated four urban populations here, one of them (Hillside Way) was one of the two low survivorship populations of the first investigation (Hitchings and Beebee, 1997). In this study, mortality in this population was one of the two highest, but was not exceptional. One possible explanation of the difference between the studies is chance over-representation, of low quality embryos in samples during the first study. Alternatively, intrapopulation competition among larvae in the Hitchings and Beebee (1997) protocol might have reflected a fitness component excluded from the current experimental design. Growth rates of larval anurans can be a non-linear function of density, with an optimum above and below which growth is stunted (a so-called Allee effect, Wilbur, 1977). Intraspecific competition among anuran larvae, including $R$. temporaria, is well documented and can be affected by relatedness (Pakkasmaa and Aikio, 2003). It is also possible that deleterious alleles might be in the process of being purged from urban frog populations. Purging can potentially reduce genetic load (Leberg and Firmin, 2008), especially when changes in population size are not rapid. This is probably true of many urban frog populations, which mostly became established within the past 50 years and have not changed noticeably in recent decades (Hitchings and Beebee, 1997). Of course our measurements of fitness were also limited by sample size, and by focusing only on part of larval development. Other aspects of fitness, such as metamorph size, would also benefit from investigation. Helper functions of CD4 cells, which express MHC class II molecules, are probably weak in the early developmental stages of larvae (Du Pasquier et al., 1989), and this may also have limited the detection of MHC-fitness correlations in our study.

There were, nevertheless, other differences between the urban and rural groups. Rural populations had more diverse growth rates than urban ones, perhaps reflecting their larger population sizes. However, the high mean growth rate of urban populations was unexpected and presumably adaptive. Growth rate of common frog larvae is partly under genetic control, with both additive and non-additive components, but can also be affected by maternal influences on egg size or quality (Laugen et al., 2002). Densities of adult frogs in urban habitats tend to be high, and individual body condition low, relative to rural sites (Beebee, 1986), suggesting that advantageous maternal factors are unlikely to account for high urban growth rates. In the absence of selection, high temperatures should increase metabolic rates and thus growth rates in ectotherms (including amphibians) purely as a consequence of increased biochemical reaction rates. However, $R$. temporaria larvae adapted to a cooler climate grew faster in northern Swedish ponds, with cool average temperatures, than in warmer ponds further south (Laurila et al., 2002). Urban ponds may be relatively cool (because of their steep sides and greater depth) compared with shallow pools used in most rural sites. Urban ponds also commonly contain gape-limited predators, especially fish, which are absent from most rural breeding sites and which keep larval densities low (Beebee, 1981). High growth rates of frog larvae in urban ponds might therefore provide a size refuge from such predators relatively quickly. However, high growth rates can also be advantageous in temporary pools by increasing the probability of metamorphosis before ponds desiccate (Laurila et al., 2002).

Neither this study nor an earlier allozyme study (Hitchings and Beebee, 1997) found significant differences in genetic diversity between urban and rural population groups. Differentiation at microsatellite loci, as shown in this study, was generally much lower than at allozyme loci and, unlike allozymes, did not indicate stronger differentiation among urban compared with rural populations. Such differences in $F_{\mathrm{ST}}$ estimates between these marker types may be at least partly accounted for by the higher average diversity of microsatellite loci (Jost, 2008). There was an overall correlation between $F_{\mathrm{ST}}$ estimates based on microsatellites and the MHC locus, but substantial differences between the two types of loci when rural and urban subgroups were analysed separately. MHC-based $F_{\mathrm{ST}}$ estimates showed the same pattern as allozymes, with significantly higher levels of differentiation in urban compared with rural habitats. This could indicate selection. No IBD was detected with microsatellites or MHC loci in urban or rural habitats (or both combined). Elsewhere $R$. temporaria showed substantial IBD using microsatellite data at large and regional scales (population groups separated by $>200 \mathrm{~km}$ ), but much less at subregional scales similar to those in this study (Palo et al., 2004; Johansson et al., 2006). Relatively high levels of gene flow across the small distances involved may account for the lack of IBD in these situations.

Earlier investigations of genetic diversity and fitness correlations in $R$. temporaria have been conflicting. In laboratory studies with multiple sibships from English populations, we found no correlations between microsatellite diversity and individual larval growth or survival (Rowe and Beebee, 2001b). However, a study of two wild Swedish $R$. temporaria populations showed significant correlations between individual microsatellite heterozygosity and size at metamorphosis (in turn usually correlated with growth rate), but not with development time (Lesbarrères et al., 2007). We found weak correlations between microsatellite diversity and mean growth rate in this study at the sibship but not at the population level, and no correlations with $\mathrm{MHC}$ diversity. However, the differences in growth rates between urban and rural sites suggest that growth rate may not be a simple indicator of fitness. There was no inverse correlation between growth rate and mortality, and an apparent selection for high growth rates in urban relative to rural populations. Overall mortality, at around $10 \%$, was not exacerbated by temperature extremes and may not have been entirely due to pathogens. The genetic diversity of dying larvae was not lower than that of survivors for either type of locus. However, there was an indication of variation in the most abundant MHC alleles, $\mathrm{C}$ and $\mathrm{H}$, between the two groups. $\mathrm{C}$ was associated with death, and $\mathrm{H}$ with survival though this observation clearly warrants corroboration in a wider 
study as well as investigation of possible reasons. Another MHC allele (R) was also potentially interesting. It was absent from all four rural populations in this study, and present in only one rural population (immediately adjacent to an urban area) in an earlier study (Zeisset and Beebee, 2009). The Woodingdean population suffered $80 \%$ reduction in adult frog population size following a Ranavirus outbreak in 2007. It was not reduced in genetic diversity at either neutral loci or at the MHC locus, but had the highest estimated allele $\mathrm{R}$ frequency (0.48) of any population. MHC class I loci may be more relevant than class II loci in the context of viral disease, and a single class I locus with high allelic diversity and Ranavirus-related associations has recently been described (Teacher et al., 2009). It is also possible that class I and class II loci are linked in R. temporaria, as they are in Xenopus (Gantress et al., 2003), and there may be more as yet undiscovered class II loci in $R$. temporaria that could vary among urban and rural populations. Also, Ranavirus pathogenesis is frequently associated with secondary bacterial infections (commonly mediated by $A$. hydrophila), amphibian resistance to which is linked to the MHC class II in Xenopus (Barribeau et al., 2008) in full-blown 'red-leg' disease (Cunningham et al., 1996). Furthermore, outbreaks of disease in frog populations are commonly associated with garden environments, possibly related to the spread of Ranavirus by ornamental fish (http:/ / www.froglife.org/disease/diseaseranavirus. html).

Overall, our results do not support the hypothesis that just measuring variation at an MHC locus is a better correlate of fitness in common frogs than variation at microsatellite loci, at least under our experimental conditions. It is of course possible that measuring variation at an MHC locus would yield more definite results when used during or after infection with a pathogen. Our results imply that a mixture of drift and selection, but primarily drift, may explain MHC as well as microsatellite diversity patterns in Sussex frog populations. This is in accord with a similar comparison made with crested newts Triturus cristatus across Europe, in which both microsatellites and MHC loci showed 'southern richness' and 'northern purity' (Babik et al., 2009). The overall correlation of inter-site $F_{\mathrm{ST}}$ estimates between microsatellites and MHC implied a role for drift, but the stronger differentiation at MHC loci compared with microsatellites in urban populations may reflect an element of selection. Garden ponds vary more in base material (concrete, plastic or fibreglass), as well as in abundance and species composition of fish and submerged macrophytes, than do rural frog ponds in Sussex (Beebee, 1981). This greater habitat heterogeneity may generate a wider variation in pathogen challenges. Anurofeca (Prototheca) richardsi is a protist infection of anuran larvae that reduces growth rate under high larval density conditions. These conditions, and this pathogen, are commoner in garden and park than in rural ponds (Wong et al., 1994).

Evidently relating adaptive variation, fitness and diversity at functional loci will require more complex investigations than those based primarily on direct correlation. The roles of specific alleles are likely to be of critical interest, as indicated above. The MHC, together with other loci such as those identified by genome scanning (Bonin et al., 2006), offers the prospect of investigating adaptive variation at the molecular level in wild populations under a wide range of environmental conditions. Further research could focus on patterns of MHC allelic variation in $R$. temporaria at higher levels of geographical scale, across which there are likely to be greater variations in selection pressures, and on populations that vary in their recent disease histories.

\section{Conflict of interest}

The authors declare no conflict of interest.

\section{Acknowledgements}

We thank the various landowners for access to the study sites and the Leverhulme Trust for financial support.

\section{References}

Antao T, Lopes A, Lopes RJ, Beja-Pereira A, Luikart K (2008). LOSITAN: a workbench to detect molecular adaptation based on a $\mathrm{F}_{\mathrm{ST}}$-outlier method. BMC Bioinformatics 9: 323.

Babik W, Pabijan M, Arntzen JW, Cogãlniceanu D, Durka W, Radwan J (2009). Long-term survival of a urodele amphibian despite depleted major histocompatibility complex variation. Mol Ecol 18: 769-781.

Balloux F, Lugon-Moulin N (2002). The estimation of population differentiation with microsatellite markers. Mol Ecol 11 155-165.

Barribeau SM, Villinger J, Waldman B (2008). Major histocompatibility complex based resistance to a common bacterial pathogen of amphibians. PLoS ONE 3: e2692.

Beattie RC, Aston RJ, Milner AGP (1991). A field-study of fertilisation and embryonic-development in the common frog (Rana temporaria) with particular reference to acidity and temperature. I Appl Ecol 28: 346-357.

Beebee TJC (1981). Habitats of the British amphibians (4): agricultural lowlands, and a general discussion of requirements. Biol Conserv 21: 127-139.

Beebee TJC (1986). Ten years of garden ponds. Br Herpetol Soc Bull 17: 12-17.

Beebee TJC (1996). Ecology and Conservation of Amphibians. Chapman \& Hall: London.

Beebee TJC (2005). Amphibian conservation genetics. Heredity 95: 423-427.

Beebee TJC, Griffiths RA (2005). The amphibian decline crisis: a watershed for conservation biology? Biol Conserv 125: 271-285.

Berlin S, Merila J, Ellegren H (2000). Isolation and characterisation of polymorphic microsatellite loci in the common frog, Rana temporaria. Mol Ecol 9: 1938-1939.

Bonin A, Tabrlet P, Miaud C, Pompanon F (2006). Explorative genome scan to detect candidate loci for adaptation along a gradient of altitude in the common frog (Rana temporaria). Mol Biol Evol 23: 773-783.

Butlin RK, Tregenza T (1998). Levels of genetic polymorphism: marker loci versus quantitative traits. Phil Trans Roy Soc Lond B 353: 187-198.

Chapuis MP, Estoup A (2007). Microsatellite null alleles and estimation of population differentiation. Mol Biol Evol 24: 621-631.

Cornuet J-M, Luikart G (1996). Description and power analysis of two tests for detecting recent population bottlenecks from allele frequency data. Genetics 144: 2001-2014.

Cunningham AA, Langton TES, Bennett PM, Lewin JF, Drury SEN, Gough RE et al. (1996). Pathological and microbiological findings from incidents of unusual mortality of the common frog (Rana temporaria). Phil Trans Roy Soc Lond B 351: 1539-1557. 
Du Pasquier IL, Schwager J, Flanjik MF (1989). The immune system of Xenopus. Ann Rev Immunol 7: 251-275.

Ficetola GF, Garner TWJ, De Bernardi F (2007). Genetic diversity, but not hatching success, is jointly affected by postglacial colonisation and isolation in the threatened frog, Rana latastei. Mol Ecol 16: 1787-1797.

Gantress J, Maniero GD, Cohen N, Robert J (2003). Development and characterization of a model system to study amphibian immune response to iridoviruses. Virology 331 254-262.

Gosner KL (1960). A simplified table for staging anuran embryos and larvae with notes on identification. Herpetologica 16: 183-190.

Goudet J (1995). FSTAT (version 1.2): a computer program to calculate F-statistics. J Hered 86: 485-486.

Hauswaldt JS, Stuckas H, Pfautsch S, Tiedemann R (2007). Molecular characterization of MHC class II in a nonmodel anuran species, the fire-bellied toad Bombina bombina. Immunogenetics 59: 479-491.

Hitchings SP, Beebee TJC (1997). Genetic substructuring as a result of barriers to gene flow in urban common frog (Rana temporaria) populations: implications for biodiversity conservation. Heredity 79: 117-127.

Johansson M, Primmer CR, Merila J (2006). History vs current demography: explaining the genetic population structure of the common frog (Rana temporaria). Mol Ecol 15: 975-983.

Jost L (2008). $G_{\mathrm{ST}}$ and its relatives do not measure differentiation. Mol Ecol 17: 4015-4026.

Kelley J, Walter L, Trowsdale J (2005). Comparative genomics of major histocompatibility complexes. Immunogenetics $\mathbf{5 6}$ 683-695.

Knopp T, Heimovirta M, Kokko K, Merila J (2008). Do male moor frogs (Rana arvalis) lek with kin? Mol Ecol 17: 2522-2530.

Laugen AT, Laurila A, Merila J (2002). Maternal and genetic contributions to geographical variation in Rana temporaria life-history traits. Biol J Linn Soc 76: 61-70.

Laurila A, Karttunen S, Merila J (2002). Adaptive phenotypic plasticity and genetics of larval life histories in two Rana temporaria populations. Evolution 56: 617-627.

Leberg PL, Firmin BD (2008). Role of inbreeding depression and purging in captive breeding and restoration programmes. Mol Ecol 17: 334-343.

Lesbarrères D, Schmeller DS, Primmer CR, Merila J (2007). Genetic variability predicts common frog (Rana temporaria) size at metamorphosis in the wild. Heredity 99: 41-46.

Palo JU, Schmeller DS, Laurila A, Primmer CR, Kuzmin SL, Merila J (2004). High degree of population subdivision in a widespread amphibian. Mol Ecol 13: 2631-2644.

Pakkasmaa S, Aikio S (2003). Relatedness and competitive asymmetry-the growth and development of common frog tadpoles. Oikos 100: 55-64.
Pidancier N, Gauthier P, Miquel C, Pompanon F (2002). Polymorphic microsatellite DNA loci identified in the common frog (Rana temporaria). Mol Ecol Notes 2: 304-305.

Piertney SB, Oliver MK (2006). The evolutionary ecology of the major histocompatibility complex. Heredity 96: 7-21.

Reed DH, Frankham R (2001). How closely correlated are molecular and quantitative measures of genetic variation? A meta-analysis. Evolution 55: 1095-1103.

Reed DH, Frankham R (2003). Correlation between fitness and genetic diversity. Conserv Biol 17: 230-237.

Romansic JM, Diez KA, Higashi EM, Johnson JE, Blaustein AR (2009). Effects of the pathogenic water mold Saprolegnia ferax on survival of amphibian larvae. Diseases Aquat Org 83: 187-193.

Rousset F (2008). GENEPOP ‘007: a complete re-implementation of the GENEPOP software for Windows and Linux. Mol Ecol Res 8: 103-106.

Rowe G, Beebee TJC (2001a). Polymerase chain reaction primers for microsatellite loci in the common frog Rana temporaria. Mol Ecol Notes 1: 6-7.

Rowe G, Beebee TJC (2001b). Fitness and microsatellite diversity estimates were not correlated in two outbred anuran populations. Heredity 87: 558-565.

Sato K, Flajnik MF, Dupasquier L, Katagiri M, Kasahara M (1993). Evolution of the Mhc-isolation of class-Ii beta-chain cDNA clones from the amphibian Xenopus-Laevis. J Immunol 150: 2831-2843.

Storfer A, Murphy MA, Evans JS, Goldberg CS, Robinson S, Spear SF et al. (2007). Putting the 'landscape' in landscape genetics. Heredity 98: 128-142.

Teacher AGF, Garner TWJ, Nichols RA (2009). Evidence for directional selection at a novel major hitocompatibility class I marker in wild common frogs (Rana temporaria) exposed to a viral pathogen (Ranavirus). PloS ONE 4: e4616.

Uller T, Olsson M (2008). Multiple paternity in reptiles: patterns and processes. Mol Ecol 17: 2566-2580.

Van Oosterhout C, Weetman D, Hutchinson WF (2006). Estimation and adjustment of microsatellite null alleles in nonequilibrium populations. Mol Ecol Notes 6: 255-256.

Werner EE (1986). Amphibian metamorphosis: growth rate, predation risk and the optimal size at transformation. Am Nat 128: 319-341.

Wilbur HM (1977). Density-dependent aspects of growth and metamorphosis in Bufo americanus. Ecology 58: 196-200.

Wong AL-C, Beebee TJC, Griffiths RA (1994). Factors affecting the distribution and abundance of an unpigmented heterotrophic alga Prototheca richardsi. Freshwater Biol 32: 33-38.

Zeisset I, Beebee TJC (2009). Molecular characterisation of MHC class II alleles in the common frog Rana temporaria. Mol Ecol Res 9: 738-745. 